\title{
Revealing the Benefits of Checklists for Preparing Projects and Research
}

Joanna Muise \& Emily Oliver

\section{Purpose}

As each of us involved in prevention and safety education know, sharing our ideas with one another for engaging learners and our experiences with employing new techniques is exciting! It can inspire creativity, support dynamic discussions, and help us to improve our own practice as professionals. Figuring out how to collect our thoughts and share our experiences however, can be tricky at times. Sometimes information gets stuck in your brain and you don't recognize to share it with others; other times you find yourself searching for a format to share your experience in so that it makes sense to someone else. Researchers will often use 'checklists' as a tool to organize information within scientific publications so that it is transparent and accurate, and nothing is missing when sharing with others. Different types of research projects can draw from different styles of checklists, each with the goal of having the information be more easily understood by others. These same tools can also be used when preparing projects and research.

\section{Description}

The GREET checklist (guideline for reporting evidence-based practice, educational interventions and teaching created by Phillips and team) offers structure for sharing education-focused projects. The full checklist includes 17 items (intervention, theory, learning objectives, EBP content, materials, educational strategies, incentives, instructors, delivery, environment, schedule, face to face time, planned changes, unplanned changes, attendance, evaluation, and schedule changes) which provide the reader with a complete picture of the intervention.

\section{Implications}

Exploring checklists and discussing the challenges they pose can help potential authors to plan their projects to ensure inclusion of vital information for a future reader. Walking through the different elements of a checklist with a particular project in mind can help support programme designers consider in a systematic way the adaptations they are making and the outcomes they hope to generate. This can help to identify what outcomes measurements can be used to best effect. The GREET tool also allows for unplanned changes which arise during the project and highlights the need to acknowledge and record these. As such, it provides a helpful guide for both project planning and writing for publication.

\section{Engagement at conference}

Delegates initially shared experiences where they have tried a different approach to first aid education (FAE) to make that learning experience better. Using a 'think, pair, share' format the delegates then started to capture details 
of their approach using a basic checklist (who was involved, what did they do differently?). The groups gradually added details to see if they could populate the full GREET checklist, recognizing which parts of their FAE stories could be challenging to share (and how to mitigate this) and details which they may not have considered sharing. The session concluded by positioning checklists as supportive tools when planning, reflecting and reporting on projects.

\section{Accompanying Session Files}

- Basic Checklist (worksheet)

- Presentation slides

- Development and validation of the guideline for reporting evidence-based practice educational interventions and teaching (GREET)

- Standards for Reporting Qualitative Research: A Synthesis of Recommendations

\section{References}

O’Brien, B. C., Harris, I. B., Beckman, T. J., Reed, D. A., \& Cook, D. A. (2014). Standards for Reporting Qualitative Research. Academic Medicine, 89(9), 1245-1251.

Phillips, A. C., Lewis, L. K., Mcevoy, M. P., Galipeau, J., Glasziou, P., Moher, D., . . . Williams, M. T. (2016). Development and validation of the guideline for reporting evidence-based practice educational interventions and teaching (GREET). BMC Medical Education, 16(1) 